\title{
The Effects of Psychological Sense of Community in Online and Face-to-Face Academic Courses
}

\author{
E. Pigliapoco and A. Bogliolo \\ University of Urbino, Urbino, Italy
}

\begin{abstract}
Recent studies have shown that the Psychological Sense of Community (PSoC) felt by students plays a key role in affecting their performance, satisfaction and persistence in academic degree programs. Hence, the lower student performance and higher dropout rates suffered by on-line courses in comparison with their face-to-face counterparts are often traced back to lower levels of PSoC caused by the lack of physical interactions among students who learn at a distance. The aim of this work is to understand to what extent the development of $\mathrm{PSoC}$ is related with teaching methods and to what extent it affects the learning process. To this purpose, we conduct a comparative analysis between the online and face-to-face versions of the same degree program, differing only for the lack of physical interactions. Multivariate analysis of variance and partial correlations are used both to isolate the effect of the teaching method on PSoC and to point out the effect of PSoC on performance, satisfaction and dropout. The outcomes of the analysis show that similar levels of PSoC and satisfaction are achieved within the two populations and that the differences observed in terms of performance and retention are mainly explained by the different composition of the corresponding cohorts.
\end{abstract}

Index Terms-Psychological Sense of Community (PSoC), elearning, learning process, student performance, student satisfaction.

\section{INTRODUCTION}

The advent of information and communication technology (ICT) in education has enabled the virtualization of schools and universities. According to Bacsich [1] here are six dimensions of virtuality that can be exploited to deliver academic degree programs at a distance: reduction of the physical presence of students in campus, non-conventional use of staff, outsourcing of network support, reduction of infrastructures, relaxation of policy constraints, flexibility of programs. Several distance education models have been proposed over the years (from the correspondence/broadcasting universities of the early 70's to today's borderless universities) and they can be classified on the basis of the dimensions of virtuality they implement and of the technical solutions they adopt. Despite the differences among the models in use, most of them implement the first dimension of virtuality to address accessibility issues and to reach wider target groups by reducing the need for physical interactions.

The implementation of the first dimension of virtuality is the main competitive advantage of virtual universities in comparison with traditional ones. However the consequent lack of physical interactions might cause a sense of isolation that might impair the psychological sense of community (PSoC) that is recognized to play an important role in student performance, satisfaction and persistence.

In this paper we try to validate the common perception that distance students feel a lower sense of community and that this is one of the reasons of their lower performance and possible dropout. Testing this hypothesis entails a fair comparison between equivalent on-line and on-campus degree programs and a statistical analysis of the relationship between PSoC and objective achievements. The analysis is made difficult because of several reasons. First, virtualization has made education accessible to a larger number of social groups with different needs and backgrounds that may affect their persistence and performance [2], thus making results of research not directly comparable. A comparative analysis between distance and face-to-face classes should consider factors such as differences in school environments and differences in student characteristics [3]. Second, the different types of virtualization make it difficult to look out general findings applicable to all distance-learning models. Third, the large number of concauses that could affect students persistence and performance makes it difficult to isolate the contribution of the PSoC.

The contribution of this study is three-fold. First, we compare a traditional degree program with an on-line degree program that has been directly derived from it by implementing only the first dimension of virtuality, so that the lack of physical interactions is the unique difference between the two courses. Second, we analyze the correlation between the perceived sense of community, the customer satisfaction and the objective indicators about students' involvement, effort, efficiency and persistence. Third, we quantify to what extent students' performance and persistence are explained by the PSoC by isolating it from other concauses through linear regression techniques and partial correlation analysis.

The rest of the work is organized as follows. In Section II we provide a survey of previous studies of PSoC in learning communities. In Section III we outline the methods applied to conduct our analysis. In particular, we introduce the case study, we define the indicators and we describe the statistical techniques used in data collection, validation and analysis. In Section IV we present and discuss the experimental results, showing that virtuality does not necessarily impair PSoC, and that the differences in student performance and dropout rate between online 
and face-to-face degree programs are mainly explained by the composition of the corresponding student populations. In Section $\mathrm{V}$ we draw conclusions.

\section{PREVIOUS WORK}

In this section we provide a brief literature overview organized in three subsections focusing on the feeling of isolation experienced in learning communities, on the importance of $\mathrm{PSoC}$ to reduce isolation and on the positive effect of PSoC on the outcomes of a degree program (expressed in terms of students' satisfaction, performance and persistence).

\section{A. Isolation}

Students' isolation can be defined as the feeling of aloneness experienced by students when they do not feel a part of something, do not belong to a group and do not participate in the meetings organized by the other peers [4]. The main reason for isolation in education is the transactional distance, defined as the psychological and communication space between learners and instructors perceived by the students [5]. Transactional distance differs from person to person and, generally, it is stronger in online programs than in face-to-face ones. In addition to psychological and geographical distance other factors can foster the feeling of isolation, such as computer illiteracy [6] and familiarity with the topics of the course [7]. Sometimes, the worsening of isolation brings students to alienation [8] corresponding to a social estrangement that has catastrophic consequences in students academic lives: failure, absenteeism, dropout [9].

In general, the correlation between the sense of isolation felt by the students and their drop-out from distance learning degree programs has been demonstrated by several studies suggesting that educational institutions must enhance connectedness among students [10] in order to stave off the feeling of isolation [11] [12] [13]. This means that they have to encourage students' participation in courses and make them aware of the importance of their contributions in the learning process [14]. In other terms, academic institutions which want to face up to student isolation and alienation must make students feel part of a learning group by fostering a psychological sense of community.

\section{B. Psychological Sense of Community}

According According to the theory of McMillan and Chavis, the PSoC is "a feeling that members have to belonging, a feeling that members matter to one another and to the group, and a shared faith that members' needs will be met through their commitment to be together" [15]. Rovai [14] distinguishes four dimensions of PSoC: spirit (friendship, cohesion, bonding among learners), trust (credibility, benevolence, confidence among learners), interaction (honesty in feedback, trust and safety among learners), common expectations (commonality of the same goals, that is learning).

PSoC contributes to reduce transactional and physical distance because students are integrated in the academic context, they never feel alone and they help each other overcome obstacles in learning. However, PSoC is not an independent variable, but it is in its turn affected by transactional and geographical distance between students and instructors. Such separation might make it impossible to develop sense of community in students, so that they feel disconnected [10] and isolated.

According to some studies, PSoC has positive effects on preventing students' burnout during their academic lives [16] and on helping socialization of students in their perspective professional lives [17], since students who feel integrated in a learning community at school will succeed in creating collaborative networks with colleagues at work [18]. Research about distance-learning also reveals that interactions among students and instructors increase the effectiveness of learning [19] and brings benefits both to individuals and to institutions [13]. On one hand, individuals experience wellbeing because they feel members of a community, they obtain support from the other students and they are more motivated in studying. On the other hand, institutions profit by the collaborative attitudes of their students and boast of the positive outcomes they achieve.

Further investigations about PSoC have pointed out that a strong sense of membership not only enhances learning support, group commitment and collaboration [20] [21] but it also increases the outcomes of the learning process by increasing students' satisfaction and performance and by reducing dropout rate, as detailed in the following subsection.

\section{Outcomes}

The success of an academic degree program is usually measured in terms of customer satisfaction, effectiveness (i.e., student performance in study) and retention (i.e., student persistence).

Satisfaction has been demonstrated to be strongly correlated with PSoC [22] [23] [24] and to play an important role in the successful accomplishment of study. Academic institutions should take under tight control the level of satisfaction with the services they provide by means of periodic inquiries on learner experience [25]. Sikora and Carroll [26] found that students who learn at a distance are on average less satisfied than students who attend face-to-face courses, suggesting that satisfaction is affected by the large number of factors which make the difference between distance-learning and face-to-face programs [27].

Many authors claim that PSoC and satisfaction are necessary to achieve successful learning outcomes [28] [29] [30] [31], while the medium is rarely the determining factor in learning effectiveness [32]. Hence, if differences are observed in the average performance of on-line and face-to-face students, they are usually explained by other factors, such as the different composition of student populations. In fact, distance education is mainly chosen by students who work and have a family, because of the higher flexibility it provides [33].

The lower sense of community and the (consequent) lower satisfaction experienced by students at the distance has been identified [34] as two of the main causes of the high dropout rate of distance learning degree programs reported in many surveys [35] [36] [37]. However, it is worth noticing that other factors, independent from PSoC, can contribute to increasing the dropout rate of distance education, such as the anxiety caused by the lack of a prompt feedback from the instructors, the frustration due to difficulties in using technologies, the confusion caused by the non-conventional study method [38]. 


\section{METHODS}

\section{A. Case study}

For our analysis we used as a case study a degree program in Applied Computer Science delivered by the University of Urbino both at the distance and on campus. The face-to-face degree program (hereafter denoted by F2F) is delivered to residential students living on campus. The online degree program (hereafter denoted by $\mathrm{OnL}$ ) has been directly derived from the F2F one by applying the world-wide campus model [39] that implements only the first dimension of virtuality, so that students never need to be physically present on campus.

The two degree programs have the same program of study, provide the same support services and share the same teaching and administrative staff, so that they are perfectly equivalent in terms of contents and services delivered to their students.

Teaching of the two degree programs is based on similar management and on equivalent principles, suitably adapted to the different communication channels. In F2F lectures the instructor makes use of slides to present the subject, while students take notes and ask questions. OnL lectures are based on the same slides, made available to students within the e-learning platform together with additional written comments. Questions can be asked during synchronous chat sessions associated with each lecture [40].

Moreover, both OnL and F2F students make use of asynchronous communication tools (i.e., forums and email) to create a virtual learning community, both groups can meet their instructors (on the phone or in person) in scheduled office hours, both of them make use of the same self-evaluation tests and assignments to monitor their own progress in learning. At the end of each course they must pass the same types of exam and they are assessed according to the same evaluation grid.

Nevertheless, the different accessibility affects the composition of the student population of the two degree programs: F2F is mainly chosen by full-time students, while OnL is chosen by so-called earner-learners, i.e. adult students who need to combine their work with higher education and consider distance learning as a good compromise between personal needs and professional upgrading.

\section{B. Data collecting}

The sample used for the statistical analysis was composed of 57 and 50 students enrolled respectively in the OnL and F2F degree programs for the first year in $2004 / 05$. At the end of the first semester, students were asked to fill in an on-line questionnaire delivered through an on-line feedback collection system allowing us to make correlations between student satisfaction and performance without disclosing students' identities. The questionnaire was made up of questions on students' personal profile (i.e., previous academic experience, job, motivation, interest, daily study effort, ...), satisfaction with the degree program (with emphasis on information service accuracy and efficiency, course organization, infrastructures and teaching) and PSoC (investigated by means of six questions outlined below). In addition, we asked a few questions about verifiable data (such as the number of taken exams, the attendance rate, ...) in order to assess the likelihood of students' answers.

Several approaches have been proposed over the years to compute PSoC indicators. All of them, however, are based on large sets of questions ( 20 or more) that were not directly applicable in our case. In fact, we needed to ask PSoC specific questions in the context of a much wider survey, making it impossible to devote too many questions to each aspect. On the other hand, the large number of questions traditionally used for psychological analysis provide the redundancy needed for cross-validation and add to the accuracy of the indicators. Using fewer questions to compute the indicators makes it necessary to test their accuracy against well-established techniques.

For this purpose, a comprehensive analysis of literature was carried out in order to point out the main aspects of PSoC and to choose a recognized technique to be used for validation. Then, a new set of six questions was defined to monitor the most relevant aspects. The questions can be retrieved in Section III.c together with the definition of the proposed PSoC indicators and with the scoring keys to be used to compute them. Independent experiments were

TABLE I.

INDICATORS

\begin{tabular}{ll}
\hline & \multicolumn{1}{c}{ Independent parameters } \\
\hline $\begin{array}{l}\text { Hours worked per day } \\
\text { Interest } \\
\text { Teaching method }\end{array}$ & $\begin{array}{l}\text { Average number of hours worked per day as declared by each student } \\
\text { Interest in the degree program declared by each student [0-10] } \\
\text { Flag taking value } 0 \text { for F2F and } 1 \text { for OnL }\end{array}$ \\
\hline Hours studied per day & \multicolumn{1}{c}{ Inter-dependent parameters } \\
Inter-student interactions & Average number of hours studied per day as declared by each student \\
Feedback accuracy & Average number of colleagues each student interacts with \\
Feedback timeliness & Perceived accuracy of the information received from the help desk [0-10] \\
Membership (1) & Perceived efficiency of the help desk [0-10] \\
SCITT (2) & Strength of the feeling of membership as directly declared [0-10] \\
\hline & PSoC indicator computed as outlined in Section 3.3 [0-10] \\
\hline Declared satisfaction & Outcomes \\
Passed exams & Overall satisfaction of each student with the degree program [0-10] \\
Average marks & Number of exams passed by each student in the first exam session \\
Persistence & Average marks obtained by each student in the exams of the first session \\
\hline
\end{tabular}


TABLE II.

PSOC INDICATORS

\begin{tabular}{|c|c|c|c|c|}
\hline \multirow[t]{2}{*}{ Variables } & \multicolumn{2}{|c|}{ OnL } & \multicolumn{2}{|c|}{$\mathrm{F} 2 \mathrm{~F}$} \\
\hline & Mean & St.Dev. & Mean & St.Dev. \\
\hline Membership (1) & 4.43 & 2.57 & 5.90 & 2.53 \\
\hline Spirit & 5.96 & 3.55 & 5.92 & 2.34 \\
\hline Commonality & 6.88 & 1.83 & 7.00 & 1.60 \\
\hline Interaction & 7.66 & 2.74 & 7.45 & 2.24 \\
\hline Trust granted & 7.17 & 1.88 & 6.57 & 1.24 \\
\hline Trust received & 6.90 & 2.30 & 6.17 & 1.49 \\
\hline SCITT (2) & 6.91 & 2.46 & 6.62 & 1.78 \\
\hline Average & 6.50 & 2.48 & 6.50 & 1.91 \\
\hline
\end{tabular}

Cronbach's alpha coefficients 0.75 .

conducted to validate the new approach against the classroom community scale (CCS) introduced by Rovai [41]. The validation procedure is detailed in Section III.d, while the results are presented and discussed in Section IV.d.

The questionnaire was kept available on the Web for one month and students were informed by e-mail. Reminders were sent weekly in the attempt of involving more reticent students who were expected to feel lower PSoC.

\section{Indicators}

Since the main purpose of this work is to investigate causal nexuses among the different aspects of the learning process, we partition the set of indicators into three categories: independent parameters, that are not affected by the learning process under study, inter-dependent parameters, that may either be affected by the independent ones or affect each other, and outcomes, that may be affected by all other parameters and represent success indicators for the learning process. The definitions of all indicators are summarized in Table I.

PSoC is expressed by two indicators defined in the 0-10 range: Membership and SCITT (that stays for Spirit, Commonality, Interaction, Trust granted and Trust received). Membership corresponds to the score of the following direct question: "How much do you feel a member of a community?". SCITT is an indicator obtained from five questions asked to investigate the dimensions of PSoC introduced by Rovai [14]: spirit, common expectation, interaction and trust. We asked "To what extent do you experience the following feelings?":

1. "low motivation to learn, feeling of loneliness, low self-esteem and isolation" (spirit)

2. "commonality of expectations and goals with other students" (commonality)

3. "reluctance to criticize, fear of criticism, retaliation and unwillingness to give honest feedback" (interaction)

4. "credibility and benevolence towards other students and instructors" (trust granted)

5. "credibility and benevolence from instructors and students" (trust received)

SCITT was computed as the weighted sum of the scores of the above questions, using -1 to weight questions 1 and 3 (expressing negative feelings) and +1 to weight questions 2, 4 and 5 (expressing positive feelings).

\section{Data Validation and analysis}

We analyzed collected data according to a three-step approach consisting of: validation, comparison and correlation analysis.

First, we conducted independent experiments to validate the new PSoC indicators introduced in Section III.c against CCS [41]. To this purpose, we prepared a questionnaire containing only the 6 questions used to compute Membership and SCITT, and the 20 questions used by Rovai [41] to compute CCS. The questionnaire was filled in by an independent sample of 38 students (hereafter called control sample) belonging to a different cohort of the same OnL and F2F degree programs. All PSoC indicators were computed for each student and the correlation coefficients among the indicators were used to demonstrate the significance of the results provided by the proposed set of questions. Furthermore, the reliability of our data was validated by comparing, wherever possible, students' answers with objective data and by computing the Cronbach's alpha coefficient to evaluate the internal consistency of subsets of indicators.

Second, we carried out a comparison between $\mathrm{OnL}$ and F2F results in terms of sample average and standard deviation. The comparative analysis took into account both the scores directly provided by the students when answering each question and additional derived figures computed from the scores of multiple questions to enable more intuitive interpretations.

Third, we used multidimensional regression analysis to investigate to what extent the PSoC explains individual performance, satisfaction and persistence and to what extent it is affected in its turn by other parameter.

\section{RESULTS AND DISCUSSION}

\section{A. Validation}

The analysis performed on the control sample demonstrated a good correlation $(0.80)$ between the PSoC indicators introduced in this paper (SCITT and Membership) and Rovai's CCS.

The reliability of the results of the survey was tested against the actual statistics of the first examination session. In particular, students were asked for the number of exams taken and passed in the first session and their answers were correlated with the corresponding actual data stored in the information system (IS). The correlation coefficients between survey and IS data were 0.85 and 0.84 for the exams taken and passed, respectively. 
TABLE III.

COMMUNITY INDICATORS

\begin{tabular}{|c|c|c|c|c|}
\hline \multirow[t]{2}{*}{ Variables } & \multicolumn{2}{|c|}{$\overline{\mathrm{OnL}}$} & \multicolumn{2}{|c|}{$\bar{F} 2 \mathrm{~F}$} \\
\hline & Mean & St.Dev. & Mean & St.Dev. \\
\hline Inter-student interactions & 2.13 & 2.44 & 8.53 & 2.94 \\
\hline Inter-student friendships & 0.85 & 1.53 & 5.93 & 3.29 \\
\hline Friendship / interactions & 0.35 & 0.40 & 0.68 & 0.33 \\
\hline
\end{tabular}

A second set of correlation analysis were performed to check the self-consistence of the survey data. For instance, a strong positive correlation was expected, by definition, between the average number of hours of study per day and the overall study effort provided on average by each student to prepare the exams of the first session (independently computed from students' answers to different questions). The ratio between the study effort per day declared by F2F and OnL students (2.34) was consistent with the ratio between the overall effort they made to prepare the exams (2.09).

To assess the reliability of non-objective data we used the Cronbach's alpha coefficient, applied to the six PSoC indicators of Table II and to the two community indicators of Table III. The coefficient expresses, in the $[0,1]$ interval, the internal consistency of a group of variables: The higher the coefficient, the higher the internal consistency. Cronbach's alpha coefficient was 0.75 for the PSoC indicators and 0.89 for the community indicators.

\section{B. Comparative results}

In this subsection we compare the results obtained from OnL and F2F students. Indicators are reported in tables in terms of sample average (Mean) and standard deviation (St.Dev.) using italic to denote derived indicators and boldface to point out the most significant results.

Table II reports the PSoC indicators for the OnL and F2F degree programs, defined on a 0-10 scale. Surprisingly enough, PSoC indicators are quite similar for the two groups. In particular, while Membership is lower for OnL students (4.43 against 5.90), SCITT is higher (6.91 against 6.62), so that the overall average value computed over the results of the six questions is exactly the same (6.50). It is worth noting, however, that the indicators of the online community are characterized by a higher standard deviation, meaning that online students experienced less uniform feelings.

A deeper difference between OnL and F2F students was found by monitoring inter-student relationships (Table III). Two indicators were used to this purpose: interstudent interactions, that is the number of colleagues each student interacted with, and inter-student friendships, that is the number of colleagues each student considered as friends. The average number of interactions and friendships reported by F2F students are respectively 4 times and 6 times larger than those reported by OnL students. The ratio between the two indicators (friendship/interactions) reveals that it is much more likely for two students to become friends if they meet each other in regular classes rather than online.

Effort indicators are reported in Table IV. The first indicator, that is the number of hours worked per day, denotes a fundamental difference in the composition of the two student populations under study. In fact, the OnL cohort was composed by $84 \%$ of full-time workers, by $12 \%$ of part-time workers and by only $2 \%$ of non-workers. In contrast, the F2F cohort was composed by $2 \%$ of fulltime workers, by $20 \%$ of part-time workers and by $78 \%$ of non-workers (i.e., full-time students). As a consequence, the estimated average number of worked hours per day is 7 h38' for OnL students and only 43' for F2F students. The different composition of the target is a fundamental point that will be discussed in detail during the regression analysis conducted in the next subsection.

The second indicator shows that online students devoted to study much less time per day than face-to-face students. This is highly motivated by the lack of time experienced by the working learners, that is quantified by the total daily effort computed by summing up the worked and studied hours per day.

The above observations seem to be in contrast with the hours of study per exam, that are higher, on average, for online students than for traditional ones. This can be explained, however, by the larger use of self-study in distance learning models. The second-last row of Table IV reports the total hours per exam obtained by adding the scheduled class hours of a standard course to the hours of study per exam (30 hours of virtual classrooms against 60 hours of regular classes). This derived indicator suggests that face-to-face students take 98 hours to prepare each exam, while online students take only 77 . We remark, however, that the derived indicator has limited reliability since it is not stratified according to the attendance rate.

Finally, students were asked to indicate the number of exams prepared for the first session. The difference between the two cohorts is apparent (see the prepared exams row of Table IV) and highly motivated by the above discussion. The total study effort (i.e., the product of the number of prepared exams by the number of hours of study per exam) of F2F students is more than twice the study effort of OnL students. This is consistent with the declared hours of study per day, as discussed above.

As a final remark, notice that the average total study effort reported in Table IV is not equal to the product of the average values of the two indicators it is derived from. This is because it was computed as the average of the individual products, rather than as the product of the averages. But the discrepancy is worth a comment since it denotes a correlation between the effort devoted to each exam and the number of exams prepared for the first session. While this correlation is slightly negative $(-0.09)$ for F2F students, surprisingly enough it is strongly positive for OnL students $(+0.73)$. 
TABLE IV.

EFFORT INDICATORS

\begin{tabular}{lcccccc}
\hline Variables & \multicolumn{2}{c}{ OnL } & & \multicolumn{2}{c}{ F2F } \\
\cline { 2 - 3 } \cline { 5 - 6 } & Mean & St.Dev. & & Mean & St.Dev. \\
\hline Inter-student interactions & $\mathbf{2 . 1 3}$ & 2.44 & & $\mathbf{8 . 5 3}$ & 2.94 \\
Inter-student friendships & 0.85 & 0.53 & & 5.93 & 3.29 \\
\hline Friendship/interactions & $\mathbf{0 . 3 5}$ & 0.40 & & $\mathbf{0 . 6 8}$ & 0.33 \\
\hline
\end{tabular}

TABLE VI.

EARLY OUTCOMES

\begin{tabular}{lccccc}
\hline Variables & \multicolumn{2}{c}{ OnL } & & \multicolumn{2}{c}{ F2F } \\
\cline { 2 - 5 } \cline { 5 - 6 } & Mean & St.Dev. & Mean & St.Dev. \\
\hline Taken exams $\left(1^{\text {st }}\right.$ session) & $\mathbf{0 . 6 0}$ & 0.86 & $\mathbf{2 . 6 2}$ & 1.03 \\
Passed exams $\left(1^{\text {st }}\right.$ session $)$ & $\mathbf{0 . 4 7}$ & 0.71 & $\mathbf{1 . 9 2}$ & 1.24 \\
\hline Self confidence ratio & 0.73 & 0.40 & 0.94 & 0.23 \\
Success ratio & 0.81 & 0.35 & 0.71 & 0.34 \\
Efficiency ratio & 0.63 & 0.43 & 0.67 & 0.35 \\
\hline
\end{tabular}

TABLE V.

OUTCOMES

\begin{tabular}{lccccc}
\hline Variables & \multicolumn{2}{c}{ OnL } & & \multicolumn{3}{c}{ F2F } \\
\cline { 2 - 3 } \cline { 5 - 6 } & Mean & St.Dev. & & Mean & St.Dev. \\
\hline Declared satisfaction & $\mathbf{6 , 3 1}$ & 1,87 & 2,13 & $\mathbf{6 , 8 2}$ & 1,24 \\
Passed exams & $\mathbf{1 , 3 1}$ & $\mathbf{3 , 2 4}$ & 2,28 \\
Average marks & $\mathbf{2 6 , 6 4}$ & 2,26 & & $\mathbf{2 4 , 6 1}$ & 2,38 \\
Persistence & $\mathbf{0 , 4 1}$ & 0,49 & & $\mathbf{0 , 8 2}$ & 0,39 \\
\hline
\end{tabular}

Effort indicators have to be compared with the outcomes of the exams to evaluate the effectiveness of the learning process. This is done in Table $\mathrm{V}$ that reports the average number of exams taken and passed by the students of the two populations. Differences are in line with the different effort they made.

For a more detailed analysis, three derived indicators are reported: self confidence, estimated by dividing the number of taken exams by the number of prepared ones, success ratio, computed as the ratio between passed and taken exams, and efficiency ratio, computed as the ratio between passed and prepared exams. The efficiency ratio is almost the same for the two populations, but it has a different breakdown: The inefficiency is mostly due to the lack of self confidence for online students (meaning that they didn't take all the exams they prepared) and to a low success rate for the face-to-face students (meaning that they didn't pass the $30 \%$ of the exams they took).

Finally, Table VI reports the outcomes evaluated after one year from enrollment in terms of: declared satisfaction, expressed on a 0-10 scale, passed exams and corresponding average marks (on a 18-30 scale) evaluated after the first three sessions, and persistence, also called retention rate, computed as the fraction of students who renewed the enrollment at the end of the first year. As observed after the first session, OnL students passed fewer exams than F2F students, while no significant differences were observed in terms of declared satisfaction and average marks. Data on students' persistence (reported in the last row of Table VI) are worth a deeper discussion. In fact, the retention rate of $\mathrm{F} 2 \mathrm{~F}$ is twice that of $\mathrm{OnL}$, even if similar levels of student satisfaction were revealed. An explanation for the different drop-out rates can be found by analyzing the boundary conditions of the two groups: the typical OnL student is a 30 -year-old full-time worker, while the typical F2F student is a 19-year-old full-time learner. As a consequence, OnL students experience difficulties independent of their personal satisfaction with the degree program and decide to drop out because of the incompatibility with their previous life choices. On the contrary, for F2F students academic studies are (at least temporarily) a life choice, so that they decide to give up only if they feel unsatisfied with this choice. This analysis is further supported by the early retention rates measured after the first semester. In fact, 33\% of OnL students dropped out soon, while a much lower percentage was obtained for F2F students (2\%) since they usually wait the end of the first academic year to possibly reconsider their life choices.

\section{Regression analysis of Outcomes indicators}

We used multiple linear regression and partial correlation analysis to investigate the effects of PSoC on the outcomes of the learning process. For each outcome indicator, we first computed the correlation coefficients with all independent and inter-dependent parameters. The indicator was then treated as a dependent variable to be modeled by means of a linear regression equation of all other parameters, treated as independent variables. To this purpose, the parameters were sorted by reverse order of their correlations with the dependent variable and incremental regression models were built. At each step of this incremental process we computed the quality of the 
TABLE IX

LiNEAR Regression OF DECLAREd SATISFACTION

\begin{tabular}{|c|c|c|c|c|}
\hline \multirow[t]{2}{*}{ Variables } & \multicolumn{2}{|c|}{ OnL } & \multicolumn{2}{|c|}{$\mathrm{F} 2 \mathrm{~F}$} \\
\hline & Mean & St.Dev. & Mean & St.Dev. \\
\hline Declared satisfaction & 6,31 & 1,87 & 6,82 & 1,24 \\
\hline Passed exams & 1,31 & 2,13 & 3,24 & 2,28 \\
\hline Average marks & 26,64 & 2,26 & 24,61 & 2,38 \\
\hline Persistence & $\mathbf{0 , 4 1}$ & 0,49 & $\mathbf{0 , 8 2}$ & 0,39 \\
\hline
\end{tabular}

TABLE VIII.

LiNEAR REgRession OF PASSED EXaMs

\begin{tabular}{|c|c|c|c|c|c|c|}
\hline \multirow[t]{2}{*}{ Variable } & \multicolumn{2}{|c|}{ Correlation } & \multirow{2}{*}{$\frac{\text { Model }}{\mathrm{R}^{2}}$} & \multicolumn{3}{|c|}{ Partial Correlation PSOC } \\
\hline & Total & Partial & & 1 & 2 & $1 \& 2$ \\
\hline Inter-student interactions & 0.416 & 0.416 & 0.173 & - & - & - \\
\hline Teaching method & -0.404 & 0.147 & 0.191 & - & - & - \\
\hline Hours worked per day & -0.370 & 0.036 & 0.192 & - & - & - \\
\hline Hours studied per day & 0.301 & 0.083 & 0.197 & - & - & - \\
\hline Membership (1) & 0.225 & 0.138 & 0.212 & 0.138 & - & - \\
\hline Feedback accuracy & -0.174 & 0.062 & 0.215 & 0.151 & - & - \\
\hline Interest & -0.163 & 0.077 & 0.220 & 0.167 & - & - \\
\hline Feedback timeliness & 0.101 & 0.168 & 0.242 & 0.099 & - & - \\
\hline SCITT (2) & -0.008 & 0.039 & 0.243 & 0.106 & 0.039 & 0.107 \\
\hline
\end{tabular}

TABLE VII.

LINEAR REGRESSION OF AVERAGE MARKS

\begin{tabular}{|c|c|c|c|c|c|c|}
\hline \multirow[t]{2}{*}{ Variable } & \multicolumn{2}{|c|}{ Correlation } & \multirow{2}{*}{$\frac{\text { Model }}{\mathrm{R}^{2}}$} & \multicolumn{3}{|c|}{ Partial Correlation PSOC } \\
\hline & Total & Partial & & 1 & 2 & $1 \& 2$ \\
\hline Interest & 0.422 & 0.422 & 0.178 & - & - & - \\
\hline Hours studied per day & -0.404 & 0.358 & 0.284 & - & - & - \\
\hline Teaching method & 0.388 & 0.117 & 0.293 & - & - & - \\
\hline Hours worked per day & 0.292 & 0.337 & 0.374 & - & - & - \\
\hline Feedback timeliness & 0.288 & 0.126 & 0.384 & - & - & - \\
\hline SCITT (2) & 0.202 & 0.013 & 0.384 & - & 0.013 & - \\
\hline Inter-student interactions & -0.190 & 0.054 & 0.386 & - & 0.033 & - \\
\hline Feedback accuracy & 0.165 & 0.251 & 0.424 & - & 0.011 & - \\
\hline Membership (1) & 0.088 & 0.189 & 0.445 & 0.189 & 0.062 & 0.190 \\
\hline
\end{tabular}

model $\left(\mathrm{R}^{2}\right)$, the partial correlation coefficient of the last parameter added to the model and the partial correlation coefficients of the PSoC indicators. Partial correlation coefficients are especially meaningful for our analysis, since they quantify the relative contribution of a given parameter to explain the variation of the dependent variable. The partial correlation coefficient between an independent variable (say, $\mathrm{x}$ ) and a dependent variable (say, y) is computed by removing the effect of all other variables. In practice, this is done by comparing two regression models of $y$, built with and without $x$ while keeping all other variables unchanged. Since in this paper we have introduced two PSoC indicators, we determine partial correlation coefficients for each of them and for their combined effect.

The results obtained by applying the above technique to the each outcome indicator are reported in Tables VII, VIII, IX and X, which share the same structure. The first column shows the names of the independent variables sorted by reverse order of correlation with the outcome indicator; the second and third columns report the total and partial correlation coefficients; the fourth column reports, in each row, the $\mathrm{R}^{2}$ of the incremental linear regression model built using the independent variables up to that row; the last three columns report the partial correlation coefficients of the PSoC indicators. The partial correlation coefficients reported in each row were computed by removing the $\mathrm{PSoC}$ indicators from the regression equation built up to that row. Column labels "1", "2" and "1 \& 2" refer, respectively, to the effect of Membership, to the effect of SCITT and to the combined effect of both of them. The partial correlation coefficients are not quantified if the corresponding indicators do not appear in the model.

Table VII reports the results of the regression analysis of the Declared satisfaction. The two PSoC indicators are among the most correlated variables, together with the indicators of interest and perceived quality of service (represented by Feedback accuracy and Feedback timeliness), while effort, boundary conditions and teaching method are much less correlated with satisfaction. Nevertheless, Teaching method has a sizeable partial correlation, meaning that it provides a significant incremental contribution to explain the residual variation of the independent variable under study. The last row of the last three columns report the partial correlation of 
TABLE X.

Linear Regression of Persistence

\begin{tabular}{|c|c|c|c|c|c|c|}
\hline \multirow[t]{2}{*}{ Variable } & \multicolumn{2}{|c|}{ Correlation } & \multirow{2}{*}{$\frac{\text { Model }}{\mathrm{R}^{2}}$} & \multicolumn{3}{|c|}{ Partial Correlation PSOC } \\
\hline & Total & Partial & & 1 & 2 & $1 \& 2$ \\
\hline Interest & 0.422 & 0.422 & 0.178 & - & - & - \\
\hline Hours studied per day & -0.404 & 0.358 & 0.284 & - & - & - \\
\hline Teaching method & 0.388 & 0.117 & 0.293 & - & - & - \\
\hline Hours worked per day & 0.292 & 0.337 & 0.374 & - & - & - \\
\hline Feedback timeliness & 0.288 & 0.126 & 0.384 & - & - & - \\
\hline SCITT (2) & 0.202 & 0.013 & 0.384 & - & 0.013 & - \\
\hline Inter-student interactions & -0.190 & 0.054 & 0.386 & - & 0.033 & - \\
\hline Feedback accuracy & 0.165 & 0.251 & 0.424 & - & 0.011 & - \\
\hline Membership (1) & 0.088 & 0.189 & 0.445 & 0.189 & 0.062 & 0.190 \\
\hline
\end{tabular}

PSoC indicators computed from the complete regression models. The non negligible values demonstrate that the effect of PSoC on student satisfaction is not masked by all other factors.

Student performance indicators (namely, Passed exams and Average marks) are analyzed in Tables VIII and IX. It is apparent that the effect of $\mathrm{PSoC}$ in the learning results is not statistically relevant. On the contrary, Teaching method has a great impact both on the number of passed exams and on the marks obtained. It is worth noting, however, that Teaching method has a positive correlation with Average marks and a negative correlation with Passed exams, meaning that OnL students passed fewer exams with better marks. A similar consideration holds for the effect of the study effort (Hours studied per day), that has a positive correlation with the number of passed exams, and a negative correlation with the average marks. This counter-intuitive result can be explained both by the inter-dependence between study effort and teaching method (OnL students have less time to study) and by the negative correlation between the number of exams and the marks taken in each of them (students who study more take more exams with lower average marks). Finally, we remark that Inter-student interactions (that can be regarded as an indicator of self-confidence and cooperation) has a great impact on the number of passed exams, while the most determining factor for learning achievements is students' Interest in the topics of the course.

Table $\mathrm{X}$ shows that PSoC indicators do not affect student persistence, while the most important independent variable is the teaching method. As discussed at the end of Section IV.b when commenting VI, the great impact of the teaching method is mainly due to the different composition of the $\mathrm{OnL}$ and F2F student populations, that also motivates the correlation with Hours worked per day and Hours studied per day. From Table X, the perceived feedback accuracy seems to have a negative effect on retention. Once again, this can be explained by the interdependence between feedback accuracy and teaching method. In fact, OnL students usually take more advantage of the support services and feel more satisfied with the feedback they receive. It is also worth noting that Inter-student interactions contribute to avoid dropout. Even if this is partly explained by the indirect effect of the teaching method (OnL students interacted less than F2F students with each other) it is worth a comment since inter-student interactions can be also taken as an objective indicator of socialization. This suggests that interactions
TABLE XI.

LINEAR REGRESSION OF MEMBERSHIP (1)

\begin{tabular}{|c|c|c|c|}
\hline \multirow[t]{2}{*}{ Variable } & \multicolumn{2}{|c|}{ Correlation } & \multirow{2}{*}{$\frac{\text { Model }}{\mathrm{R}^{2}}$} \\
\hline & Total & Partial & \\
\hline Feedback timeliness & 0.458 & 0.458 & 0.209 \\
\hline Inter-student interactions & 0.372 & 0.432 & 0.357 \\
\hline Interest & 0.282 & 0.310 & 0.419 \\
\hline Feedback accuracy & 0.248 & 0.158 & 0.433 \\
\hline Hours worked per day & -0.137 & 0.221 & 0.461 \\
\hline Teaching method & -0.106 & 0.019 & 0.461 \\
\hline Hours studied per day & 0.102 & 0.019 & 0.461 \\
\hline
\end{tabular}

TABLE XII.

LINEAR REGRESSION OF SCITT (2)

\begin{tabular}{lcccc}
\hline Variable & \multicolumn{2}{c}{ Correlation } & & Model \\
\cline { 2 - 3 } \cline { 5 - 5 } & Total & Partial & & $\mathrm{R}^{2}$ \\
\hline Interest & $\mathbf{0 . 4 8 5}$ & $\mathbf{0 . 4 8 5}$ & & 0.235 \\
Feedback timeliness & 0.241 & 0.107 & & 0.244 \\
Feedback accuracy & 0.205 & 0.009 & & 0.244 \\
Teaching method & $\mathbf{0 . 1 3 4}$ & $\mathbf{0 . 0 5 0}$ & & 0.246 \\
Inter-student interactions & 0.131 & 0.384 & & 0.357 \\
Hours worked per day & $\mathbf{0 . 1 0 6}$ & $\mathbf{0 . 0 8 6}$ & & 0.362 \\
Hours studied per day & -0.106 & 0.096 & & 0.368 \\
\hline
\end{tabular}

are useful to prevent dropout even if they do not necessarily imply an emotional involvement.

\section{Regression analysis of PSoC indicators}

In this section we report the results of the regression analysis conducted to evaluate to what extent PSoC indicators are explained by other independent and interdependent factors (regarded as independent variable). Results are separately reported for the two indicators in Tables XI and XII. The first column shows the name of the independent variables, sorted by reverse correlation order; columns 2 and 3 report their total and partial correlations; column 4 reports the $\mathrm{R}^{2}$ of the incremental regression models including the variables up to each row. Independent parameters, according to Table I, are highlighted in boldface.

From the tables we observe that both PSoC indicators are mainly affected by the interest in the subject of the degree program, by the feedback received from the staff and by the interactions with other students. Hence, the more students are motivated, interact with each other and receive accurate and timely feedback from the academic institution, the more they feel part of a community. Surprisingly enough, teaching method and boundary conditions (represented by the number of hours worked 
per day) are not so relevant. In fact, they have a low correlation and an even lower partial correlation with both PSoC indicators. We also remark that SCITT and Membership do not provide equivalent information. This is demonstrated by the differences between Tables XI and 12 , and by the different roles of SCITT and Membership in the regression models of the outcome indicators (Tables VII-X).

As a final consideration, notice that regression analysis was used in this context only at the purpose of studying the causal relations among the PSoC indicators and the parameters of the learning process under study. We didn't expect the linear regression models to fully explain the behavior of the dependent variables. In fact, most of the models reported in Tables VII-XII have a coefficient of determination $\left(\mathrm{R}^{2}\right)$ lower than 0.5 , meaning that they don't follow all variations of the corresponding parameters. Nevertheless, they provide meaningful partial correlations useful to point out the incremental contribution of each indicator. The low value of $\mathrm{R}^{2}$ can be traced back either to the presence of other factors that are out of the scope of this work, or to the non-linear nature of the causal relations.

\section{CONCLUSION}

In this paper we have carried out a statistical analysis aimed at answering the following two questions:

1. To what extent does the lack of physical interactions among online students affect their psychological sense of community?

2. To what extent does the psychological sense of community explain the different outcomes of online and face-to-face degree programs?

We used as a case study a BS degree program in Applied computer science delivered both online and faceto-face. Data were collected by means of a comprehensive online questionnaire including six questions used to compute PSoC indicators. The answers provided by online and face-to-face students were first used to compare the two groups and then combined to investigate causal relations by means of multiple linear regression and partial correlation analysis.

The comparative analysis pointed out significant differences in the composition, performance and persistence of the two groups. Online students are mostly full-time workers over 30, they take on average less than 2 exams per year and they have a dropout rate larger than $50 \%$. Face-to-face students are mostly full-time learners under 20, they take on average more than 3 exams per year and only $18 \%$ of them decide to give up studying after the first academic year. On the other hand, no sizeable differences were observed in terms of average marks, declared satisfaction, and PSoC.

Partial correlations showed that PSoC has a low impact on the objective outcomes of the learning process (expressed in terms of Passed exams, Average marks, and Persistence) while it affects the individual perception of the service received (represented by Declared satisfaction). On the contrary, Teaching method is almost irrelevant for student satisfaction while it has a great impact on all objective outcome indicators. This can be explained by the socio-demographic features that the teaching method induces on the student population. In fact, on-line degree programs are the natural choice of learner-earners, while face-to-face degree programs are preferred by full-time students. The different boundary conditions motivate the different performance and dropout rate. This is in accordance with the results published by Cerejo et al. [33], discussed in Section II.c.

Finally, the regression analysis conducted on PSoC indicators confirmed that they are not significantly affected by the teaching method, while they are mainly affected by personal motivations and perceived quality of service both for online and face-to-face students.

These observations are in line with the conclusions drawn by Hara and Kling [38] (reported in Section II.c) and can be the starting point for further discussions. Since the empirical study highlights the most important aspects for distance-learning students, the results achieved suggest the actions that could be undertaken by academic institutions for enhancing student performance and degree program success. In particular, institutions could:

- provide effective information support in order to enhance user satisfaction and boost the feeling of being part of a community which pays attention to students' needs;

- encourage interactions among students to obtain a benefit both in terms of performance (number of exams passed) and $\mathrm{PSoC}$;

- stimulate students' interest in order to reduce dropout rate.

From a research perspective, two main directions can be taken into consideration for future work: refinement of the regression models and generalization of the results.

As already discussed in the paper, the linear regression models implicitly built to conduct partial correlation analysis show low determination coefficients (reported in Tables VII to XII under column labeled $\mathrm{R}^{2}$ ). This means that they fail to completely model the behavior of the dependent variables under study. Future investigations could focus on searching for additional independent variables explaining the residual variation, in order to build accurate predictive models that were beyond the scope of this work. Such an approach could change the perspective from which the phenomenon is seen (possibly pointing out the importance of factors which are usually pushed into the background) and, as a consequence, help institutions to fully understand and exploit the causal relations driving the learning process.

Finally, it is worth underlining that the results presented in this paper are based on a sample of only 107 students taken from a single case study. The proposed methodology is to be applied to other degree programs in order to widen the sample and to generalize the results obtained.

\section{REFERENCES}

[1] Bacsich, P. (2004). The e-university compendium, Higher Education Academy. UK.

[2] Cavanaugh, C. (2002). Distance Education Quality: Success Factors for Resources, Practices and Results. In R. Discenza, C. Howard, \& K. Schenk (Eds.), The design and management of effective distance learning programs. (pp. 171-189). Hershey, PA: Idea Group Publishing.

[3] Rovai, A.P., Wighting, M.J., Lucking R. (2004). The Classroom and School Community Inventory: Development refinement, and validation of a self-report measure for educational research, The Internet and Higher Education, 7, 263-280. 
[4] Misanchuk, M.M, Dueber, B. (2001), Sense of Community in a Distance Education Course. Mid-South Instructional Conference Murfreeboro, TN.

[5] Moore, M.G. (1993). Theory of transactional distance. In D. Keegan (Ed.), Theoretical principles of distance education, New York: Routledge, 22-38.

[6] Fyfe, S. (2000). Collaborative learning at a distance: The Human Biology experience. Paper presented at the 9th Annual Teaching Forum, Perth Australia, Retrieved December 12,2005 from http://www.lsn.curtin.edu.au/tlf/tlf2000/fyfes.html

[7] McInnerney, J. M., Roberts, T. S. (2004). Online Learning: Social Interaction and the Creation of a Sense of Community. Educational Technology \& Society, 7 (3), 73-81.

[8] Rovai, A.P, Wighting, M.J. (2005). Feelings of alienation and community among higher education students in a virtual classroom. The Internet and Higher Education, 8, 97-110.

[9] Mau, R. Y. (1992). The validity and devolution of a concept: Student alienation. Adolescence, 27(107), 731-741.

[10] Kerka, S (1996). Distance Learning, the Internet and the world wide web. ERIC Digest (Eric Document Reproduction Service No. ED 395 214)

[11] Palloff, R.M., Pratt, K. (1999), Building Learning Communities in Cyberspace, Effective strategies for the online classroom, San Francisco: Jossey-Bass.

[12] Morgan, C.K., Tam, M. (1999). Unravelling the Complexity of Distance Education Student Attrition. Distance Education, 20(1), 96-108.

[13] Haythornthwaite, C., Kazmer, M., Robins, J., and Shoemaker, S. (2000). Making connections: Community among computersupported distance learners. Paper presented at the Association for Library and Information Science Education 2000 Conference, San Antonio, TX. Retrieved December 13, 2005, from: http://www.alise.org/conferences/conf00_Haythornthwaite_Makin g.htm

[14] Rovai, A.P. (2002). Building Sense of Community at a Distance. International Review of Research in Open and Distance Learning.

[15] McMillan, D. W., Chavis, D.M. (1986). Sense of Community: A definition and theory. Journal of Community Psychology, 14(1), 623.

[16] McCarthy, M.E., Pretty, G.M.H., Catano, V. (1990). Psychological Sense of Community and Student Burnout. Journal of College Student Development, 31 (May), 211-216.

[17] Lave, J, Wenger, E. (1991). Situated learning: legitimate peripheral participation. New York: Cambridge University Press

[18] Haythornthwaite, C. (1998). A social network study of the growth of community among distance learners. Information Research, 4(1).

[19] Kelsey, K. D., \& D'Souza, A. (2004). Student motivation for learning at a distance: Does interaction matter? Online Journal of Distance Learning Administration, 7, (2).

[20] Dede, C. (1996), The evolution of distance education: Emerging technologies and distributed learning. American Journal of Distance Education, 10(2), 4-36.

[21] Wellman, B. (1999). The network community: An introduction to networks in the global village. In Wellman, B. (Ed) Networks in the Global Village. P.1-48. Boluder, CO: Westview Press.

[22] Shea, P., Swan, K., Fredericksen, E., Pickett, A. (2002) Student Satisfaction and Reported Learning in the SUNY Learning Network. Elements of Quality Online Education, Needham, MA: SCOLE (ISBN 0-9677741-2-8).

[23] Johnston, J., Killion, J., Oomen, J. (2005). Student Satisfaction in the Virtual Classroom. The Internet Journal of Allied Health Sciences and Practice, 3(2).

[24] Rafaeli, S. \& Sudweeks, F. (1997). Networked interactivity. Journal of Computer-Mediated Communication, 2(4).

[25] Chute, A,G., Thompson, M. M., Hancock, B W. (1999). The McGraw-Hill handbook of distance learning. New York: McGraw-Hill.

[26] Sikora, A.C., Caroll, C.D. (2002). Postsecondary education descriptive analysis reports (NCES 2003-154). US. Department of Education, National Center for Education Statistics, Washington, DC: U.S. Government Printing Office.
[27] Keegan, D. (1990). The foundations of distance education. 2nd ed. London: Croom Helm.

[28] Kazmer, M. M. (2000). Coping in a distance environment: Sitcoms, chocolate cake, and dinner with a friend. First Monday, 5(9)

[29] McLellan, H. (1999). Online education as interactive experience: Some guiding models. Educational Technology, 39(5), 36-42.

[30] Gunawardena, C.N., \& Zittle, F.J. (1997). Social presence as a predictor of satisfaction within a computer-mediated conferencing environment. The American Journal of Distance Education, 11(3), 8-26.

[31] Picciano, A.G. (2002). Beyond student perceptions: issues of interaction, presence, and performance in an online course. Journal of Asychronous Learning Networks (JALN), 6(1).

[32] Russell, T. L. (1999). The 'No Significant Difference Phenomenon' (fifth edition), North Carolina State University Office of Instructional Telecommunications.

[33] Cerejo, M.V.P., Young, J., Wilhelm, R.W. (2001). Factors Facilitating Student Participation in Asynchronous Web-Based Courses, The Journal of Computing in Teacher Education, 18 (1), 32-39.

[34] Tinto, V. (1993). Leaving college: rethinking the causes and cures of student attrition. (2nd edition). Chicago: University of Chicago Press.

[35] National Center for Educational Statistics (1999). Distance education at post-secondary education institutions. Retrieved 13 December,2005 from http://nces.ed.gov/pubs2000/2000013.pdf

[36] Carr, S (2000). As distance education comes of age, the challenge is keeping the students, The Chronicle of Higher Education, 46(23), A39-A41.

[37] Frankola, K. (2001). The E-learning taboo-high dropout rates: Best practices for increasing online course completion rates. Syllabus, June 2001, 14-16

[38] Hara, N., Kling, R. (2001), Student distress in web-based distance education. Educause Quartely, 3, 68-69.

[39] Pigliapoco, E., Bogliolo, A. (2005). Global Accessibility of Higher Education: Using ICT to Build a Worldwide Campus, in Proceedings of EISTA-05.

[40] Pigliapoco, E., Torrisi, G., Messina, M., Bogliolo, A. (2006). "LoL Classroom: A Virtual University Classroom Based on Enhanced Chats", in Proceedings of ICL-2006.

[41] Rovai, A.P. (2002b). Development of an Instrument to Measure Classroom Community. The Internet and Higher Education, 5, 197-211.

\section{AUTHORS}

E. Pigliapoco received the Laurea degree summa cum laude in "Languages and Business Culture" and the MS degree in "E-Learning management" from the University of Urbino, Italy, in 2005 and 2006, respectively. She's currently with the Information Science and Technology Institute (ISTI) of the University of Urbino, Urbino, 61029 Italy (e-mail: erika.pigliapoco@uniurb.it).

A. Bogliolo, received the Laurea degree in Electrical Engineering and the Ph.D. degree in Electrical engineering and Computer Science from the University of Bologna, Italy, in 1992 and 1998, respectively. In 1995 and 1996 he was visiting the Computer Systems Laboratory (CSL), Stanford University, Stanford, CA. From 1999 to 2002 he was Assistant Professor with the Department of Engineering (DI) of the University of Ferrara, Ferrara, Italy. He's currently Director of the Information Science and Technology Institute (ISTI), University of Urbino, 61029 Italy (e-mail: alessandro.bogliolo@uniurb.it).

This work was supported in part by Fondazione Cassa di Risparmio di Pesaro.

Manuscript received 26 November 2007. Published as submitted by the authors. 